\title{
Chapter 8 \\ Combining In-Depth Biographical Interviews with the LIVES History Calendar in Studying the Life Course of Children of Immigrants
}

\author{
Andrés Gomensoro and Raúl Burgos Paredes
}

\subsection{Introduction}

The use of the life course perspective to study migration is of increasing interest in the field. A majority of the research on first- and second-generation residents is based on quantitative methodological designs that mainly focus on different aspects of their insertion into the host society. This type of research takes objective indicators as inspiration such as educational attainment, position in the labor market, social networks, citizenship and, level of proficiency in the host country's language. On the other hand, some studies use qualitative approaches to study the lives of descendants of immigrants. The aim of those studies is to understand people's subjective evaluations of life events and trajectories. We think that both approaches study two sides of the same coin.

The biographical approach and the life course perspective share many features. Both study the lives of individuals, groups or cohorts using retrospective or longitudinal methodological designs. Researchers using those two approaches study lives in context (social, historical, structural contexts, etc.). They also consider individuals'

\footnotetext{
A. Gomensoro $(\square)$

University of Applied Sciences Western Switzerland (HES-SO), Social Work, Geneva, Switzerland

National Centre of Competence in Research Overcoming Vulnerability: Life Course Perspectives (NCCR Lives), Geneva, Switzerland

e-mail: Andres.Gomensoro@unil.ch

R. Burgos Paredes

National Centre of Competence in Research Overcoming Vulnerability: Life Course Perspectives (NCCR Lives), Geneva, Switzerland

Life Course and Inequality Research Center (Lines), University of Lausanne,

Lausanne, Switzerland

e-mail: Raul.BurgosParedes@unil.ch
}

C. Bolzman et al. (eds.), Situating Children of Migrants across Borders and

Origins, Life Course Research and Social Policies 7,

DOI 10.1007/978-94-024-1141-6_8 
lives to be composed of different interrelated dimensions, linked to other individuals' lives, and that individuals are not entirely socially determined (the idea of agency). ${ }^{1}$ Nevertheless, each approach and its respective methodology allows us to study two different but complementary dimensions of life. Life course studies generally use quantitative methodological tools (mainly standardized questionnaires and life event calendars) to obtain objective life events and objective trajectories of groups or cohorts based on a regular and chronological time scale in months or years. For their part, studies based on the biographical approach focus more on the subjective selection of important life events and the subjective interpretation of life events and trajectories, mainly by using qualitative interviews. This reconstruction of the life story during the interview is not based on a regular and chronological time scale but on a subjective time scale graduated by those events that the interviewee considered significant (Demazière 2003).

In order to grasp both objective and subjective events and the trajectories of individuals' lives, and simultaneously chronological and subjective time scales, we propose the use of the LIVES history calendar (Morselli et al. 2013; Morselli et al. 2016) — which is a life history calendar — and an in-depth biographical interview. The first tool comes from the life course perspective, and the second comes from the biographical tradition. At the same time, our goal is to account for the methodological benefits of both tools, such as a more systematic process and increased validity of the "objective" life course data gathered by using life event calendars (Belli and Callegaro 2009) as well as in-depth exploration of subjective life stories obtained by using in-depth biographical interviews. To apply this idea, we tested and used the combination of semi-structured biographical interviews and the LIVES history calendar in studying the transition to adulthood of the children of Albanian-speaking immigrants in Switzerland.

Scholars have only recently started turning to a combination of a life event history calendar and biographical narratives to capture relevant aspects of migrant life courses. Nico (2015) introduces the life history calendar in the study of transition from youth to adulthood in Portugal, although the paper does not describe the operationalization of the tool in great detail. From a social psychology perspective, Barbeiro and Spini (2015) use the LIVES history calendar and in-depth interviews to investigate the representations of justice and injustice perceived by Portuguese migrants in Switzerland. We add to this emerging literature by providing a detailed description of how our mixed-mode research design developed and was tested and implemented.

In the following Sect. 8.2, we introduce the biographical approach and life course perspective as well as develop common points between them. Next, we present the tools: the in-depth biographical interview and the LIVES history calendar. Finally, we describe the mixed-mode design developed within the research project "From youth to adulthood: descendants of immigrants insertion in the Swiss society" funded between 2010 and 2014 by the Swiss National Centre of Competence in Research LIVES: Overcoming Vulnerability: Life Course Perspective (NCCR LIVES).

\footnotetext{
${ }^{1}$ See the introduction chapter of this volume.
} 


\subsection{Historical Development and Common Points of the Biographical Approach and the Life Course Perspective}

Researchers within the biographical approach focus their attention on "the interrelation between individual and society, and how broader perceptions and modes of thought are represented and monitored within the specific situation and outlook of individuals and groups" (Roberts 2002: 34). They essentially analyze subjective biographical data about the individual's entire existence, such as life stories or written biographies, whether about a short period of life or some specific dimensions of life. "A life story gives us a vantage point from which to see how one person experiences and understands life, his or her own especially, over time. It enables us to see and identify threads and links that connect one part of a person's life to another, that connect childhood to adulthood" (Atkinson 2002: 126).

For its part, the life course perspective takes as a conceptual basis some principles that guide empirical research. The most used principles are historical time and place, timing, linked lives, and agency. These principles, in turn, are translated into concepts to investigate trajectories, phases, events and transitions in the life course (Levy et al. 2005), in which transitions correspond to "changes in a state that are more or less abrupt" (Elder 1985:32), such as from being single to married.

Qualitative biographical methods and the life course perspective share some common points, such as the interrelation between individuals' lives and social systems, for which they take into account historicity (Ferrorrati in Bertaux 1981). However, there are also some divergences regarding the methodological approach and the focus of the study, such as the study of objective events and trajectories versus subjective events and trajectories as well as quantitative versus qualitative research designs.

The methodological tools we use to study the lives of children of immigrants are situated at the crossroads of those two main approaches in the social sciences. This will allow us to collect information on objective events and trajectories as well as to their subjective evaluation by respondents. In the following part, we will briefly introduce the main steps in the development of the biographical and the life course approaches to outline the links and complementary elements between them as well as the respective methodological tools we use.

Stories of fictitious or real people have long been part of human lives through oral and written history. According to Pineau and Le Grand (2013), the first written life histories in the Western world appeared in the fourth century B.C. in Greek culture. The thinkers of that time developed the Socratic maieutic and used "bios" (life histories) to better "know thyself." Later, a well-known example of a biography is the New Testament, written around the first and second century, which tells the life history of Jesus. Since antiquity, the use of biographies became more and more significant, such as the Confessions of Augustin (400 A.D.), the development of novels (Middle Ages) and Rousseau's Confessions (eighteenth century) (Pineau and Le Grand 2013: 22-37). ${ }^{2}$

\footnotetext{
${ }^{2}$ See Fabre et al. (2010) for a more precise description of the apparition of written biographies in human history and ethnology.
} 
More recently, in the nineteenth century, social scientists such as ethnographers and anthropologists demonstrated a true interest in exploring biographical corpora and, more specifically, in studying the biographies of individuals or groups. According to Goodson (2001) and Mucchielli (2009: 78), the first social science researchers to use biographical data were W. H. Rivers, an anthropologist interested in the genealogy of Tuba Indians and Melanesians at the end of the nineteenth century; S. Barrett, who published Geronimo's Story of His Life; and F. Boas, a famous GermanAmerican anthropologist who collected life stories of Pueblo Indians in the 1920s. Moreover, anthropologists in general have long been interested in stories of common people as a way to understand their way of life, common practices and culture.

In the following years, researchers from the Chicago School were the first sociologists to take biographies into account as valid and interesting data giving blueprints to understand societal facts. The Polish Peasant in Europe and America, published between 1918 and 1920 by William I. Thomas and Florian Znaniecki (1974), is known as the first major study in migration research and also as the first step in the development of the biographical approach. In this inquiry, Thomas and Znaniecki studied the effects of the migration process (seen as a radical societal change) on the reorganization of Polish immigrants' and their families' lives. They compared and contextualized the effects of the migration process with the effects of the societal change in the Polish peasant society, "from the old forms of organization that had been in force, with only insignificant changes, for many centuries, to a modern form of life" (Thomas and Znaniecki 1974: 74). The Polish Peasant is the first significant sociological study to use an extensive amount of biographical material. Indeed, they recollected, published and commented on hundreds of letters to and from immigrants to the United States of America. They also used material from their case study - the autobiography of the Polish immigrant Wladek Wiszniewski (Thomas and Znaniecki 1974, Part IV). As a complement, while in Poland, Znaniecki studied the archives of a Polish newspaper and carried out many interviews with people desiring to emigrate. For his part, Thomas explored records from different parishes and social institutions in Chicago (Madge 1963). The authors considered subjective qualitative data to be an indispensable part of the methodological design. From their perspective, the "social values" and "attitudes" of the individuals as well as "objective elements" have to be taken into account in producing social theory. Thus, Thomas and Znaniecki, and the Chicago School in general, used biographical material and, more specifically, life stories as a way to understand social change.

Thereafter, many colleagues of Thomas and Znaniecki used biographies and case studies to understand urban life in Chicago (Becker 1970). ${ }^{3}$ This period of prolific use of biographical and qualitative data in the Chicago School was followed by a radical reversing of the trend. With the decline in influence of the Chicago School,

\footnotetext{
${ }^{3}$ E.g., Park's studies on immigration (The Immigrant Press and Its Control 1922; Race and Culture 1950); Frazier (The Negro Family in Chicago 1932) and Hugues as well as the studies on delinquency of Shaw (The Jack Roller 1930; The Natural History of a Delinquent Career 1931; Shaw et al., Brothers in Crime 1938); Conwell and Sutherland (The Professional Thief 1937); Thrasher (The Gang 1928); Wirth (The Ghetto 1928); and Anderson (The Hobo 1923).
} 
quantitative and survey methods became hegemonic from the 1930s to the 1970s during what is called the positivistic revolution. However, many scientists developed qualitative methodological tools, analytical frameworks and paradigms during this period of positivism, determinism and social constructivism. ${ }^{4}$

The biographical approach re-emerged in sociology during the 1970s and 1980s, principally in Europe and North and South America, as a result of the renewed interest in the classical studies of the Chicago School, the influence of ethnology and anthropology $y^{5}$ and the rediscovery of the subjectivity of actors (Beaud 1996: 226). During the same period, the life course perspective emerged with the now classical work of Elder (1974). ${ }^{6}$ Using quantitative and longitudinal databases on students in the United States, he demonstrated the effect of historical events and socioeconomic and social contexts on individuals' lives and trajectories. Seven years later, in 1981, Biography and Society," a collective book edited by Bertaux (1981), regroups many articles based on biographical data from international researchers such as Kohli, Ferrorrati, Elder and many others. This book became a classic text that demonstrates the international scope of biographical research in sociology but, at the same time, the "variety of uses" that have been made of it (Bertaux and Kohli 1984).

The biographical approach and the life course perspective are varied in terms of the theoretically studied objects, studied groups (or social milieu), number of participants (in the biographical approach, this ranges from a sample of one, the study of one individual's life, to a sample of over one hundred individuals) and disciplines (sociology, anthropology, psychology, history, etc.). Bertaux (1980) and Heinritz and Rammstedt (1991) had already noted the multitude of theoretical objects (deviance, lived experiences, values, social roles, identities, lifestyles, life trajectories, etc.) and studied populations (workers, farmers, employees, teachers, immigrants, families, young adults, elder people, delinquents, drug addicts, etc.) at the beginning of the resurgence of the biographical approach. Since that time, the diversity of theoretical objects and studied populations within the biographical approach and the life course perspective has increased in many disciplines. Additionally, their analytical focus has increasingly become interdisciplinary.

Studies based on the biographical approach also use different kinds of data and tools. Denzin (1970) and Bertaux (1980) distinguished between two different types of biographical data. On the one hand, there are life history data, of which the biography (or life story) is only one part of the biographical corpus, and which may also be composed of statistical data, interviews with other persons, observations, etc. On

\footnotetext{
${ }^{4} \mathrm{We}$ can mention the development of the qualitative interview in its various forms, supported by the democratization of recording (Platt 2012), including, among others, the work of Merton and Kendall (1946) as well as the emergence of subjective paradigms that are radically distant from the deductive approach, such as symbolic interactionism (Strauss 1959; Blumer 1969), the grounded theory of Glaser and Strauss (1967), phenomenology (Schütz 1967; Berger and Luckmann 1967) and hermeneutics (Ricoeur 1983).

${ }^{5}$ We can mention, for example The Children of Sanchez by Oscar Lewis (1961).

${ }^{6}$ In a personal conversation in Geneva in April 2013, Glen Elder mentioned the fact that his work was influenced by the way that William Thomas took the interaction between individual lives and the social structure into account.
} 
the other hand there is the life story, for which the principal biographical data corpora are the biographies themselves (how individuals tell or write their own lived stories or a part of them). Depending on the research questions and methodological designs, oral life stories are obtained using different types of more or less semistandardized or open interviews such as biographical interviews (Demazière and Dubar 1997), life story interviews (Bertaux 1997; Atkinson 1998, 2012) and narrative interviews (Schütze 1983; Rosenthal 2004). Life course studies generally develop retrospective or longitudinal designs to obtain databases on objective events and trajectories. The most used tool to gather life course data is the (longitudinal or retrospective) standardized questionnaire, even though the use of the calendar to gather retrospective data has increased since the late 1980s (Morselli et al. 2016).

Biographical studies have been quickly criticized, by quantitative researchers as well as by sociologists who were used to qualitative approaches (for example Bourdieu 1986; Passeron 1990). The debate was also intense between researchers within the biographical approach. This made the biographical approach evolve into two principal analytical tendencies. ${ }^{7}$ We can bring forward the opposition between "realism" or the "contextual approach" and "constructivism" or the "interpretative approach" (Roberts 2002; Nilsen and Brannen 2010). The first one, the "contextual approach," emerged in France (Daniel Bertaux) and Germany (Fritz Schütze) after the rediscovery of the "realism" of the Chicago School approach and under the influence of symbolic interactionism and also phenomenology. Researchers who use this analytical focus study the lived life (which is composed of the biographical events of one's life) and the told story - the self-interpretation of the life (Wengraf 2000) in context, in relation to time and space. The second approach, the "interpretative approach," emerged under the influence of hermeneutics and narrativism. In this approach, researchers such as Norman Denzin and Ulrich Overmann consider life stories as fictions created by interviewees from real and sometimes imagined events. The analytical focus is more on the construction of the story.

Thus, we can see that despite some differences (such as qualitative and subjective $v s$. quantitative and objective), the two approaches have many common points. Both approaches appeared during the same decade under the influence of the classical work of Thomas and Znaniecki (1974). Both approaches focus on the interrelation between (social, structural, historical) contexts and lives. Finally, both take into account the time dimension of life in a diachronic perspective. Now that we have introduced the historical development and common points of these perspectives, we will present, in the following section, the methodological tools we applied in our empirical study.

\footnotetext{
${ }^{7}$ To see an extensive description of the different types of analytical focuses by country and author, refer to Bertaux and Kohli (1984); Heinritz and Rammstedt (1991); Apitzsch and Inowlocki (2000); and Nilsen and Brannen (2010).
} 


\subsection{The In-Depth Biographical Interview}

Many types of interviews focus their attention on the life stories and life trajectories of individuals. The names of the types of interviews vary by author and theoretical tradition (for example, the life story interview, the biographical interview, the retrospective interview, the narrative interview, the in-depth interview, etc.). These different types of interviews differ in terms of data (based on chronological time and objective data, on subjective time and subjective data or both) and interview method (more or fewer open-ended questions, use of a more or less flexible interview guide or not at all, etc.). In addition, different types of interviews are used to study a large variety of topics and life periods (the whole life or some specific topics and periods of life). In the following lines, we present the kind of interview we decided to combine with the use of the LIVES history calendar.

We rely on Demazière's definition of the biographical interview. According to him, "every biographical interview expects, as a minimum, that interviewees tell something about their lives, or about some dimensions of their biography (professional, familial, affective life, etc.), and doing it in the framework of an open, indepth, comprehensive exchange, contrary to the succession of closed questions which is typical of questionnaires." He also added that to be considered biographical, an interview has to generate stories or "an argued narrative of his life course" (Demazière 2003: 76). Thus, the biographical interview allows us to obtain life stories or, in other words, an adopted position of the interviewee on his or her own life course, as "every life story is an interpretation of the past" (Battagliola et al. 2005: 239) from an interaction process between the interviewee and the interviewer. The told story of the interviewee will necessarily be influenced by the circumstances of the interview (time, place, mood of the participants, questions by the interviewer, answers of the interviewee, relationship of trust developed between the interviewee and the interviewer, etc.). Although we must be aware of this, our aim is also to obtain and compare the told story, or the "subjective reconstruction" with the "objective" events and periods filled in the calendar, to study both sides of the story and improve the validity and quantity of the biographical data. It is also important for us to not only focus on individual life stories as a selection made by interviewees of important events and periods in their life, but also to adopt a larger scope to capture the effects of the social interactions that influenced the production of their life story (Demazière 2011).

Contrary to the completely open interview methods often used in the biographical approach, we carry out in-depth semi-structured interviews using a flexible interview guideline that include different topics (see empirical applications below). It was important for us to develop interview guidelines that include the precepts of the life course perspective (such as the idea that lives are linked or the effect of historical time on individual lives) to develop a solid methodological design in which both tools are complementary. Using semi-structured interviews allows us to avoid forgetting the discussion of some important topics and, at the same time, gives us a flexible framework that allows us to explore important and unexpected life events or 
topics deeply. Thus, the use of the interview guidelines is different in every interview, especially according to each interviewee. Some interviewees willingly provide their life stories and discuss by themselves the important topics we are interested in. In this case, the guidelines are used more as a checklist and as a basis for topics to be more precisely discussed. Some other interviewees are less willing to speak and produce their life story. In this other case, we carried out more of a semi-structured interview. Yet, our goal was to encourage the interviewees to produce life stories as often as possible. To do so, it is paramount to place interviewees in a narrative dynamic at the first contact, from the presentation of their participation in the survey ("We want you to tell us your life story, your educational path, etc.") to the implicit contract between the interviewee and the research team, the introduction of the interview and finally during the interview by asking open-ended questions (Demazière and Dubar 1997: 88).

\subsection{The LIVES History Calendar}

Life calendars are useful tools for collecting objective/retrospective data on life events and their timing. There are different designs in the literature concerning life calendars, but three main features are always present (Glasner and Van der Vaart 2009: 335): there is always a graphic representation of time; there are several topics or life dimensions delimited by researchers called life domains; and the interviewee is encouraged to report events in each of these life domains (see Fig. 8.1). This representation as a calendar seems to increase the quality of the retrospective data because of the tool's specific, structured format, which invites the interviewee to place specific time events with precision. Some studies have verified (Freedman et al. 1988; Mayer 2006; Reimer and Matthes 2007) that life calendars simplify the task of remembering important life events. Memory is stimulated because of the graphic representation of a person's life along with its respective order/sequence. The interviewee uses some key events to remember other events from the same life dimension using sequential retrieval strategies or from other dimensions of life using parallel retrieval strategies (Belli and Callegaro 2009). The calendar is also convenient for the interviewer because it can be of great help for relaunching questions in domains where information might be missing or is unclear.

Another advantage of life calendars is their flexibility and the applications that can be done with them. For example, life calendars can be used to question people of different ages or cultural backgrounds (Axinn et al. 1999). In addition, the interviewer also has an important task when filling out a calendar because, instead of focusing on specific questions (like in more traditional questionnaires), he or she has to adapt to the situation and the way the interviewee responds. It is for this particular reason that interviewers ideally have to be trained before using a life events calendar in an interview. The disadvantages of a life calendar can include the time it takes to complete, the total interview time if there are other questionnaires to conduct, the complex coding of responses and the training of the interviewers (Glasner and Van der Vaart 2009: 343-344). 

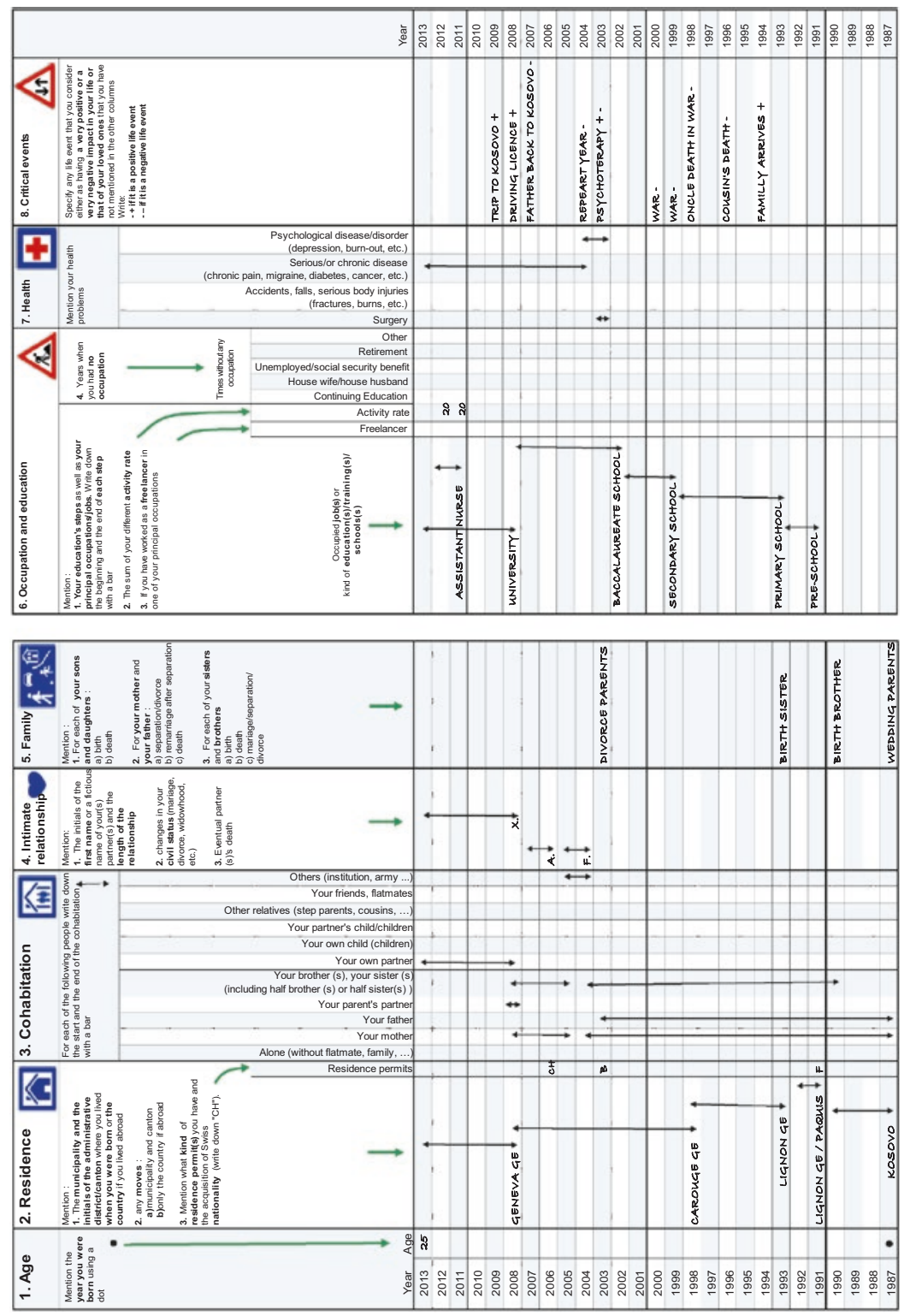
A relevant example of the application of life calendars to study migrant populations is that of Engel et al. (2001). In this study, one of the objectives was to collect detailed occupational histories of migrant farm workers to determine their cumulative lifetime pesticide exposure (Engel et al. 2001: 503). As the job history of these workers is too complex to truly capture all of their different employers and work locations for a given year via a traditional questionnaire, the authors of this study tried to use a life calendar in the second round of data collection with some special icons to represent several life domains and the participants' employment history. Comparing the quality and quantity of the data gathered using these two tools, the authors unquestionably concluded that the life calendar provided more adequate and richer data precision of work histories among a population with limited literacy and large variation in terms of employment.

The LIVES history calendar (see Fig. 8.1) was designed by a research team within NCCR LIVES to investigate objective events together with subjective perceptions of them. It was mainly inspired by previous work done at the Institut National des Etudes Démographiques in Paris (Morselli et al. 2013) and was designed to be self-administered. The calendar is a graphical representation of time under several life dimensions such as place of residence (see column 2); type of residence permit and nationality (see column 2); cohabitation (see column 3); intimate relationships and changes in civil status (see column 4); family events such as births, deaths, marriages and divorces (see column 5); educational and professional path (see column 6); and health-related issues (see column 7) as well as one last column labeled critical events (see column 8), where the respondent is free to write whatever positive or negative event he or she has lived that had a deep impact on her/his life. The calendar's timetable starts from birth (see column 1), unlike other applications, which are mainly focused on specific periods.

In the following sections, we will introduce how we applied the aforementioned methodological tools.

\subsection{Empirical Application: The Study of the Transition from Youth to Adulthood Among the Children of Albanian-Speaking Immigrants in Switzerland}

The combined use of the LIVES history calendar and in-depth biographical interview was implemented in the context of a large research project entitled "From youth to adulthood: second-generation residents' incorporation into Swiss society," which was part of NCCR LIVES. The transition to adulthood was examined from three main and complementary dimensions: the educational and professional dimension, the family dimension and the citizenship dimension. Our main goals were to describe and understand the transition to adulthood among children of a more recent and vulnerable immigrant "ethnic" group - the children of Albanian-speaking immigrants - and to compare this transition with those of children of Swiss parents 
with similar social backgrounds as well as of children of immigrants with other ethnic or national backgrounds. The data collection strategy is based on a mixedmethod design involving, firstly, an innovative quantitative survey in Switzerland based on the administration of a household questionnaire, a network questionnaire and the LIVES history calendar; and secondly, a qualitative survey based on indepth biographical interviews and LIVES history calendars conducted with about 70 children of Albanian-speaking immigrants as well as 40 interviews (without calendars) with some of their parents performed in the Geneva, Lausanne and Zurich cantons. The interviews and calendars with the young participants were conducted in the local language (French in Geneva and Vaud, and German in Zurich), while the parents had the choice to conduct the interview in Albanian or in the local language. We foresaw the possibility that the parents would prefer to be interviewed in Albanian; thus, we recruited Albanian-speaking interviewers. A majority of the parents indeed preferred to do the interview in Albanian. We can consider the target population in the research project's survey as being hard to reach, mainly because we relied on sociological characteristics of the definition of "second generation" to define the population (in our case, individuals who spent the majority of their compulsory education in Switzerland and with Albanian-speaking parents from the former Yugoslavia) and not on commonly used statistical characteristics (such as nationality or place of birth). Thus, we could not use official statistical registers to find potential participants. We can also consider the population as being hard to recruit, firstly because we were looking for young and "busy" participants who are often not interested in surveys. Secondly, many of those young people have experienced socially devaluated situations and vulnerable situations (for example, dropping out of school, unemployment, problems with police and justice, etc.). It is not easy to speak about those events and situations, especially with an interviewer with high education and with whom the interviewee is not familiar. Thirdly, some of them and their parents have experienced stigmatization and/or insecure legal status (undocumented, asylum seekers, provisional admission, etc.), which can place them into a state of mistrust in everything that is related to the state or an official organization (such as NCCR LIVES). Finally, according to the desired sampling (half in vocational education or lower and half in tertiary education), we expect that at least one-quarter of the participants had manual vocational education. In general, they lack the writing and reading skills needed to fill the calendar by themselves. Thus, the characteristics of the studied population made us confront major methodological challenges in the field. In the following part of this chapter, after describing the interview guidelines, we will discuss more precisely how we combined in-depth biographical interviews with LIVES history calendars for the qualitative study of the transition to adulthood among 45 children of Albanian-speaking immigrants from 18 to 27 years old living in Geneva and Lausanne. 


\subsubsection{The Interview Guidelines}

Our aim was to combine the use of the foreshowed LIVES history calendar and indepth biographical interviews to obtain the frequency, length, sequencing and situation in time of the principal life events as well as to obtain a life story or the subjective evaluation of those life events. We used the interview guidelines as technical support for the interviewer during the interview, as a list of pertinent questions that were tested and approved before the interview and as a reminder. We definitively did not see the guidelines as a questionnaire or a list of questions to necessarily ask the interviewee in the same order. To summarize, the use of these guidelines allowed us to discuss the important topics and explore unexpected elements at the same time. The interview guide developed for this survey is composed of three principal parts related to the main life domain dimensions of the transition from youth to adulthood: the educational and professional dimension, the family dimension (household, relationships, parenthood, marriage, intergenerational relationships, etc.) and the citizenship dimension (legal status and nationality, belonging, changes at the age of majority, social and political participation, etc.). To this, we added questions on discrimination, transnationalism and health. The first part of the interview guide - but not necessarily the beginning of the interview, as we will see later-allowed us to directly enter the principal topic of the research (the transition from youth to adulthood) using open-ended questions. This first part was composed of some questions about the participants' subjective perception of the transition to adulthood, such as, "Today, do you consider yourself as a youth, as an adult or both at the same time?" followed by some relaunch questions and questions on the subjective definition of youth and adulthood (for example, "According to you, what is a youth/adult?"). By doing this, we were willing to place the interviewee in a narrative position and introduce the main topic of the interview at the same time. For each dimension or topic of the interview guidelines, we developed one introductory question whose purpose was to initiate the interviewee story on the topic (for example, for the education dimension: "Can you describe/narrate to me your education from the beginning to the end/to today?"). Every dimension was composed of many sub-sections and questions that could be asked if more precision was needed or to induce the interviewees to place themselves in a narrative position (for example: "Can you tell me what made you choose to continue to post-compulsory education?" or "What post-compulsory education did you consider at that time?"). Thus, our interview strategy was to start from general dimensions to sub-dimensions and finally to particular and precise questions. For instance, we asked some questions about the educational trajectory in general to obtain a general picture and then asked questions about each stage of the educational trajectory in a chronological order. At the end of the interview, as frequently done in qualitative interviews, we left the "door open" to the interviewee by asking the question, "Would you like to add something about anything we spoke about already or about something important we have not mentioned yet?." The answer to this final question often helped us to discover something not expected or emphasized an important opinion or element in the interviewee's life. 


\subsubsection{Testing the Combination of the LIVES History Calendar and the In-Depth Biographical Interview}

Our starting point was to combine the LIVES history calendar and in-depth biographical interviews (based on the interview guide described before) to study children of Albanian-speaking immigrants. The characteristics of the studied population described before had a huge impact on how we combined these two methodological tools. We tested three different combinations of those tools to try to obtain the best benefits of the combination for studying our particular population.

Our first intention was to auto-administrate the LIVES history calendar (by sending the calendar and a document that explains to the participant how to fill it in at home, and then waiting about one week for him or her to fill it out and send it back by mail) and then interviewing the participant face to face. We identified many advantages. For example, the interviewees had time to fill in the calendar. They could search for the precise information in documents and ask their parents and family members for help. The interviewees could also identify what we were interested in (the different dimensions of the calendar), thus making the reconstruction of the life story more structured and less confusing during the interview. In addition, the interviewer could prepare the interview (some specific questions) according to the data on the calendar. Both the interviewer and interviewee could use the calendar during the interview as a reference document to situate questions in time and dimensions, to more easily reconstruct the interviewee's life story in a chronological order. The interviewer could also compare the data on the calendar with the story and ask for specifics if something was different. We also identified some disadvantages that made us change our procedure. In fact, one disadvantage of the calendar is that it asks for many personal life, details which people may not be ready to reveal to someone they have never met. We can see here the importance of building a relationship of trust between the researcher and the participant. In addition, the entire participation (from the first call to the end of the interview) took time, usually from one week to one month. The auto-administration of the calendar took about $40 \mathrm{~min}$ and required somewhat higher involvement and skills (reading and writing) from the participants. We noted that the auto-administration of the calendar was not adapted to some participants with low educational attainment. Many of the participants arrived with an empty calendar at the interview, and some of them no longer wanted to participate. We also tested conducting interview first and then autoadministrating the calendar afterwards, but this procedure was not interesting, principally because it was difficult to get back the calendar and we lost the opportunity to use the calendar during the interview.

After that first test, we considered the possibility of meeting the participants twice: one time to fill in the calendar and one time for the interview (or the inverse). This configuration is interesting principally for two reasons. Firstly, the administration of the calendar will take less time (between 10 and $40 \mathrm{~min}$ ) when it is done jointly, with the support of the interviewer, rather than self-administrated. Secondly, the procedure is more adapted to the less-educated participants because they do not 
need to read the instructions and the interviewer can fill in the calendar if desired (only a few participants with manual educational training asked the interviewer to fill in the calendar). Thirdly, it is also interesting because the two different tools, which use two different approaches (open-ended questions during the interview and precise questions for the calendar) to gather two different types of data, are concretely separated in terms of time and meetings. Unfortunately, this procedure is not adapted to this specific young population, which is often reluctant to participate in surveys that require a high time investment. In addition, for many participants, it is difficult to set up an appointment and to concretely meet on the day of the appointment. Nevertheless, this procedure can be adapted to other populations.

In view of the disadvantages of the two procedures introduced before, we developed a specific procedure to complete both the calendar and then the in-depth biographical interview, in only one face-to-face meeting. During the test phase, we noticed that this procedure was adequate for studying the children of Albanianspeaking immigrants, specifically the lower-educated and less motivated ones. In fact, the interviewer could fill in the calendar if the participant required. The fulfillment of the calendar took less time (between 10 and $40 \mathrm{~min}$ ) compared with the auto-administration mode (30-50 $\mathrm{min})$, the total time of participation to the survey was shorter (between 90 and $120 \mathrm{~min}$ ) and everything was done in one meeting to avoid the risk of a missed appointment. Thus, the attrition between meetings was avoided, and the interviewer and the interviewee could both use the calendar during the interview. Yet, at first glance, we can identify a major issue. How can we begin with a closed-question dynamic and then switch to an open-ended question dynamic without restraining the development of the life story? In the following lines, we detail the procedure and the different strategies used during its implementation in the field to resolve or at least to minimize the effects of this issue.

The procedure of face-to-face participation in one meeting was composed of four principal parts. The first part, from the meeting with the respondent to the beginning of the interview, was composed of small talks (to talk about something that was not important, such as the weather, the traffic, the holidays, a common friend, etc.) to smoothly enter into the interview; thereafter, we provided more information on the study and on the research institute, the conditions of participation, the introduction to the recording and the participant's consent. The second part of the participation was the fulfillment of the LIVES history calendar. The third part was the in-depth biographical interview. Finally, the last part was the conclusion to the participation where we asked the participant if he/she wanted to add anything more and if we could eventually contact them in the future and then thanked them for their participation.

Throughout the face-to-face participation and even before the meeting, we developed three principal strategies that allowed us to fulfill in the calendar without having a negative impact on the development of the life story, or at least to minimize a negative impact. The first strategy consisted of placing the participants in a narrative mode by inviting them to tell their story; speak as much as they wanted; explain precisely how they lived a specific event, period or path; ask for details; and support the narration with relaunch questions. This strategy was applied throughout the par- 
ticipation in the survey. At the first contact by email or telephone, when we introduced the survey, we explained that we were interested in the participants' life story, that we wanted the participants to tell their story and that every single story is unique and interesting for us. When we met the participants again, we reminded them that we wanted them to share their experience with us. At the beginning and during the filling out the calendar, we encouraged the participants to speak about what they were writing (for example, "Please don't hesitate to tell me things about the events you mention on the calendar") and asked questions during the fulfillment to invite the interviewees to speak (for example, the interviewer would look at the calendar and say: "So, I see that you travelled for one year between high school and university." The interviewee may reply: "Yes, I wanted to have a break because ..."). Finally, the main purpose of the in-depth biographical interview was to produce the life story, so we encouraged the participants to tell their story by asking open-ended questions (for example, "Can you tell me your memories of your educational path, from the first day until the end/today?) and using relaunch questions to obtain more precise information on a specific event or period (for example, "You told me you chose to do a tinsmith apprenticeship. What made you go down this road?"). The use of this strategy was effective in about 6 cases out of 10. Thus, while recording, we obtained first some comments and narrative development during the filling out of the calendar and then a life story constructed by the interviewee and stimulated by the questions relaunched by the interviewer.

In some cases ( 3 of 10 participants), the interviewees did not speak much during the fulfillment of the calendar, despite the discursive incentives of the first strategy. They answered with short sentences and did not go into details. In this case, we set up a second strategy, which was to clearly distinguish the two parts of the participation: the calendar and the in-depth biographical interview. When we finished the calendar, we provided a break and explained that we were beginning a new part of the study. We helped the participants to clearly see the difference between the two dynamics (writing and commenting during the fulfillment of the calendar and talking freely during the in-depth interview) by stating, "You completed the calendar. You can leave it on the table so you can look at it if you need to and eventually complete or correct it. Now, we will begin another part of the survey, I would like you to tell me your story, your path, your life experience. To begin, I have one question ..." This strategy helped the participants to speak freely but it was not guaranteed. In fact, some of the participants did not speak easily, as they were shy or did not like to share their experience.

In another cases, participants began to tell their life story during the filling out of the calendar. Generally, the participants began speaking about one dimension of their life related to the column they were filling out. In this case, our third strategy was to maintain and encourage the narration. We did not stop the story; on the contrary, we supported it with follow-up questions and then continued onto other topics. In short, we reversed the procedure and took full advantage of the voluntary development of the life story to go back later to the fulfillment of the calendar. Such cases were rare but advantageous for the interviewer, who only needed to orient the narrative toward the topics of interest. 
With the help of these three strategies, we minimized the effects of the type of information requested by the fulfillment of the LIVES history calendar to develop the life story. On the contrary, we maximized our chances to obtain the life story as well as a completed calendar within the short duration of the participation. The implementation of the "calendar then interview in one meeting" procedure was satisfying for the study of our specific population, provided that we paid attention to the willingness of participants to develop a narrative. Thus, in this case, adapting the method to each participant's characteristics (if he or she spoke easily or not at all) using the three strategies introduced before was fundamental to obtaining satisfying data quality and quantity.

\subsection{Contributions and Further Applications}

In the following, we introduce some advantages and limitations of our method that emerged during the implementation of this procedure. At the end of the section, we discuss possible future applications of the method.

Several scholars have argued that the use of a history calendar, as compared to a standard biographical questionnaire, improves the validity and quantity of the data collected (Barbeiro and Spini 2015; Belli 2007; Belli and Callegaro 2009; Glasner and Van der Vaart 2009; Martyn and Martin 2003). The calendar is a flexible tool that allows the development of sequential (in the same column or domain of life) and parallel (by comparing the data in different dimensions of life) retrieval strategies (Belli and Callegaro 2009: 35). In addition to the advantages related to the use of a history calendar, there are specific advantages in combining it with narrative biographical interviews.

First, during the interview, both the interviewer and the interviewee can compare the data on the calendar to improve the quality of the data. If the interviewee remarks on a difference, he or she can correct what he or she said or correct the date of an event or period on the calendar. If the interviewer observes some differences, then he or she can point it out and ask for more precise information. Sometimes, during the in-depth biographical interview, the interviewee remembered and added some life events on the calendar (particularly for the last column about subjective life events).

Second, the graphical representation of the respondent's life trajectory proves to be very useful at the moment of the narrative interview. The interviewer can ask questions about a specific dimension and life period and concretely point to it on the calendar with a finger. The interviewee can situate the question on his or her own life course and easily understand the question. Alternatively, it is the interviewee who tells his or her own story, also while answering to a question, while pointing at the relevant event or year on the calendar with a finger..

Third, the calendar may make possible the narration of a difficult life event (parental death, illness or negative critical events) that would otherwise be left aside in the narrative interview. In fact, it is sometimes easier for the interviewee to write 
a traumatic event on a calendar than to mention it during an open interview (Martyn and Martin 2003). It is also easier for the interviewer to ask a question about a difficult life event when it is already mentioned on the calendar by asking, "Can you tell me more about this event?." In addition, having a specific column for "type of residence permit and nationality" allowed us to discuss the consequences of legal status and nationality on the transition to adulthood and identity in a subtle way.

Interviewer: Now, we are going to talk a little bit on permits. So, you had an "F" permit until 2003 , then the "B" permit and then you obtained Swiss nationality at 18 years old (interviewer points to each permit in column 2 of the calendar, see Fig. 8.1). ${ }^{8}$

Serena: Yes.

Interviewer: According to your experience, did you feel differences in your everyday life with those permit changes?

Serena: From "F" to "B," yes, enormous differences. Because with the "F," we've always been afraid of being expulsed to Kosovo. During my entire childhood, it was very difficult. I remember when we received a letter in 1999 (she points to 1999 on the last column of the calendar) to inform us that we have to leave Switzerland, during the war (in Kosovo). The letter said that we had to pack our stuff and that someone would come to drive us to the airport. That was really traumatic for us. So, when we had the "B" permit, it was a relief. (...) Then, my naturalization was specifically to travel. I didn't feel that I belonged more to Switzerland. It was not related to my identity.

Interviewer: So, you don't feel Swiss even though you have Swiss nationality?

Serena: No, not at all (...).

Fourth, the interview can use the calendar to identify turning points or critical periods in the participant's life course and directly ask a question about how the participant managed this turning point.

Interviewer: I can see that, in 2003 and 2004, you faced a lot of changes. Your parents divorced, you mother sent you to a home for young girls, you repeated the first grade of high school, you begun to have abdominal chronic pain. How did you manage all that?

Serena: It was very difficult because I was good at school before my parents divorced, so it was a big change. Everything was changing. My mother began working, so my brother, my sister and I were often alone. And, I was in charge of them, so I didn't have a lot of time to invest in my homework.

Interviewer: So, you also had a lot of new responsibilities?

Serena: Yes, the problem was not only at school, but also in the family (...) (after that, she added depression in 2003 and 2004 to column 7 and psychotherapy in 2003 to column 8; see Fig. 8.1).

Fifth, the combined use of open-ended and structured approaches to the collection of life trajectories allows the interviewee to rely on the calendar to develop her/ his biographical narrative. In fact, in a classical semi-structured interview, the narrative is a co-construction made by the interaction between the interviewee and interviewer. The interviewer's questions influence and orient the narrative toward the topics of interest. In our new configuration, the interviewee produces the narra-

\footnotetext{
${ }^{8}$ The "F" permit is for "persons who have been ordered to return from Switzerland to their native countries but in whose cases the enforcement of this order has proved inadmissible (violation of international law), unreasonable (concrete endangerment of the foreign national) or impossible (for technical reasons of enforcement)." The "B" permit is for "foreign nationals who reside in Switzerland for a longer period of time for a certain purpose, with or without gainful employment" (www.bfm.admin.ch).
} 
tive under the influence of the interviewer and the calendar. The calendar influences the interviewer's questions but above all structures the interviewee's narrative. For example, if we asked the interviewee to describe his or her educational pathway from the beginning to the end, in many cases she/he would rely on the calendar, look at it and develop his or her narrative according to the different periods mentioned on it. Thus, the calendar helps to structure the narrative in a chronological order without forgetting a period. As a result, the calendar is not a limitation but most often a motivation and a source of support that helps the development and structuring of the life story. In our field research we noticed that when the interviewee started his or her narrative before the end of the fulfillment of the calendar, his/her story was less structured then in the opposite case. Obviously, the presence of the calendar is not an asset for open-ended interviews.

Last, the LIVES history calendar and the in-depth biographical interview produced different types of data that allowed us to approach and embrace the transition from youth to adulthood in two complementary ways. With the calendar, we obtained precise events and periods of different dimensions of life in a chronological order (for example, see Fig. 8.1 column 5: divorce of parents in 2003 or column 6: baccalaureate school from 2002 to 2006). The interview allowed us to know the interviewees' subjective interpretation of those life events and periods and, at the same time, to understand how they and their social and institutional contexts influenced or defined the events and periods written on the calendar. For instance, we noticed a huge difference in many cases, and sometimes a contradiction, between the interviewees' nationality and their subjective sense of belonging and national identification. Our methodological procedure allowed us to disentangle elements in the lives of people that would not be evident if used separately.

As with most methods, the combination of the LIVES history calendar with indepth biographical interviews also does not lack limitations. Firstly, during the interviews, the calendar sometimes became a rigid frame to some interviewees. They tended to only talk about the topics covered by the calendar. In this case, the calendar influenced the development of the life story too much. To prevent this effect, the interviewer has to mention other topics developed upon the interview guidelines and use multiple relaunch questions to orient the narrative toward other topics. Regarding the validity of the data, we identified that a fulfillment error on the calendar could be introduced into the narrative, on very rare occasions. The last limit we identified is a challenge. In fact, when combining the two tools, we obtained two types of data. The calendar provides "objective" data that can be analyzed statistically with quantitative methods, and the interviews provide "subjective" data that can be used to perform a narrative analysis. These two types of data increase the complexity of the analysis, which requires an integrated analysis method that links both types of data (see also Barbeiro and Spini 2015 for a discussion of the advantages and disadvantages of the mixed-methods data collection using the history calendar and narrative biographical interviews).

The LIVES history calendar was developed to study every kind of population (natives, immigrants or their children) in any situation (in Switzerland or abroad) and stage of life (young adults, adults, elderly). Our interview guidelines were spe- 
cifically developed to interview young second-generation residents by including specific topics such as transnationalism, legal status, nationalities, naturalization, citizenship, belonging and discrimination. Thus, this method allowed us to study the transition to adulthood in a complementary way (objective and subjective) and by considering the complexity of different situations among the children of immigrants (born in Switzerland or born abroad and arriving during early childhood, Swiss or foreign, different types of residence permits, etc.). The tools we presented may be combined for other populations and with different research aims in the life course and biographical perspective; however, it is important to test the implementation procedures and adapt them based on experience in the field. Evidently, the interview guidelines need to be adapted to the research aims.

The implementation of a mixed-mode design tracing life trajectories and biographical narratives represents an improvement in how we approach the life courses of children of immigrants, since it simultaneously accounts for "objective" events and transitions together with personal goals motivating actions, or as Nico (2015:1) writes, "the meanings and narratives of individuals on the matters of their own trajectories."

Acknowledgements This paper benefited from the support of the Swiss National Centre of Competence in Research LIVES-Overcoming Vulnerability: Life Course Perspectives, which is financed by the Swiss National Science Foundation (Grant number: 51NF40-160590).

\section{References}

Apitzsch, U., \& Inowlocki, L. (2000). Biographical analysis. A German school? In P. Chamberlayne, J. Bornat, \& T. Wengraf (Eds.), The turn to biographical methods in social science. Comparative issues and examples (pp. 53-70). London: Routledge.

Atkinson, R. (1998). The life story interview. London: Sage Publications.

Atkinson, R. (2002). The life story interview. In J. Gubrium \& J. Holstein (Eds.), Handbook of interview research (pp. 120-141). Thousand Oaks: Sage.

Atkinson, R. (2012). The life story interview as a mutually equitable relationship. In J. Gubrium, J. Holstein, A. Marvasti, \& K. McKinney (Eds.), The Sage handbook of interview research: The complexity of the craft (pp. 115-128). Thousand Oaks: Sage Publications.

Axinn, W., Pearce, L., \& Ghimire, D. (1999). Innovations in life history calendar applications. Social Science Research, 28(3), 243-264.

Barbeiro, A. \& Spini, D. (2015). Calendar interviewing: A mixed methods device for a life course approach to migration. LIVES Working Paper 2015/39.

Battagliola, F., Bertaux-Wiame, I., Ferrand, M., \& Imbert, F. (2005). A propos des biographies: Regards croisés sur questionnaires et entretiens. In R. Miller (Ed.), Biographical research method. London: Sage.

Beaud, S. (1996). L'usage de l'entretien en sciences sociales. Plaidoyer pour l'«entretien ethnographique». Politix, 9(35), 226-257.

Becker, H. (1970). The life history and the scientific mosaic. In H. Becker (Ed.), Sociological work: Method and substance (pp. 63-73). Brunswick: Transaction books.

Belli, R. (2007). Examining the impact of event history calendar interviewing on data quality from disadvantaged respondents. Paper presented at the conference on the event history calendar method. U.S. Census Bureau. Suitland. 
Belli, R., \& Callegaro, M. (2009). The emergence of calendar interviewing. In R. Belli, F. Stafford, \& A. Duane (Eds.), Calendar and time diary. Methods in life course research (pp. 31-52). Thousand Oaks: Sage Publications.

Berger, P., \& Luckmann, T. (1967). The social construction of reality. London: Penguin Books. Bertaux, D. (1980). L'approche biographique: Sa validité méthodologique, ses potentialités. Cahiers Internationaux de Sociologie, 69, 197-225.

Bertaux, D. (Ed.). (1981). Biography and society. Thousand Oaks: Sage Publications.

Bertaux, D. (1997). Les récits de vie. Paris: Nathan.

Bertaux, D., \& Kohli, M. (1984). The life story approach: A continental view. Annual Review of Sociology, 10, 215-237.

Blumer, H. (1969). Symbolic interactionism: Perspective and method. Englewood Cliffs: Prentice-Hall.

Bourdieu, P. (1986). L'illusion biographique. Actes de la recherche en sciences sociales, 62-63, 69-72.

Demazière, D. (2003). Matériaux qualitatifs et perspectives longitudinales. La temporalité des parcours professionnels saisis par les entretiens biographiques. In 10 Journées d'études CéreqLasmas-IdL, Caen, 21, 22 et 23 mai 2003 (pp. 75-89). Marseille: Céreq.

Demazière, D. (2011). L'entretien biographique et la saisie des interactions avec autrui. Recherches qualitatives, 30(1), 61-83.

Demazière, D., \& Dubar, C. (1997). Analyser les entretiens biographiques. Paris: Nathan.

Denzin, N. (1970). The Research Act. Chicago: Aldine.

Elder, G. H. (1974). The children of the great depression. Chicago: University of Chicago Press.

Elder, G. H. (1985). Perspectives on the life course. In G. Elder (Ed.), Life course dynamics: Transitions and trajectories, $1968-1980$ (pp. 23-49). Ithaca: Cornell University Press.

Engel, L., Keifer, M., \& Zahm, S. (2001). Comparison of a traditional questionnaire with an icon/ calendar-based questionnaire to assess occupational history. American Journal of Industrial Medicine, 40(5), 502-511.

Fabre, D., Jamin, J., \& Massenzio, M. (2010). Jeu et enjeu ethnographique de la biographie. L'Homme, 195-196, 7-20.

Freedman, D., Thornton, A., Camburn, D., Alwin, D., \& Young-DeMarco, L. (1988). The life history calendar: A technique for collecting retrospective data. Sociological Methodology, 18, $37-68$.

Glaser, B., \& Strauss, A. (1967). The discovery of grounded theory: Strategies for qualitative research. Chicago: Aldine.

Glasner, T., \& Van der Vaart, W. (2009). Applications of calendar instruments in social surveys: A review. Quality and Quantity, 43(3), 333-349.

Goodson, I. (2001). The story of life history: Origins of the life history method in sociology. Identity: An International Journal of Theory and Research, 1-2, 129-142.

Heinritz, C., \& Rammstedt, A. (1991). L'approche biographique en France. Cahiers Internationaux de Sociologie, 91, 331-370.

Levy, R., Ghisletta, P., Le Goff, J.-M., Spini, D. and Widmer, E. (2005). Incitation for interdisciplinarity in Life Course Research. In R. Levy, P. Ghisletta, J.-M. Le Goff, D. Spini, \& E. Widmer (Eds.), Towards an interdisciplinary perspective on the life course (pp. 361-391). Coll advances in life course research (Vol. 10). Amsterdam/Boston: Elsevier.

Lewis, O. (1961). The children of Sanchez. New York: Random House.

Madge, J. (1963). The origins of scientific sociology. London: Tavistock Publications.

Martyn, K. K., \& Martin, R. (2003). Adolescent sexual risk assessment. Journal of Midwifery \& Women's Health, 40, 213-219.

Mayer, K. U. (2006). Retrospective longitudinal research: The German life history study. New Haven: Yale University, Center for Research on Inequalities and the Life Course.

Merton, R., \& Kendall, P. (1946). The focused interview. The American Journal of Sociology, 51(6), 541-557. 
Morselli, D., Spini, D., Le Goff, J. M., Gauthier, J.-A., Brändle K., Mugnari, E., et al. (2013). Assessing the performance of the Swiss Panel LIVES calendar: Evidence from a pilot study. LIVES working papers (Vol. 28, pp. 1-56).

Morselli, D., Dasoki, N., Gabriel, R., Gauthier, J.-A., Henke, J., \& Le Goff, J.-M. (2016). Using life history calendars to survey vulnerability. In M. Oris, C. Roberts, D. Joye, \& M. ErnstStähli (Eds.), Surveying human vulnerabilities across the life course (pp. 177-199). New York: Springer.

Mucchielli, A. (Ed.). (2009). Dictionnaire des méthodes qualitatives en sciences humaines. Paris: Armand Colin.

Nico, M. L. (2015). Bringing life "back into life course research": using the life grid as a research instrument for qualitative data collection and analysis. Quality and Quantity, 1-14.

Nilsen, A., \& Brannen, J. (2010). The use of mixed methods in biographical research. In A. Tashakkori \& C. Teddlie (Eds.), SAGE handbook of mixed methods in social \& behavioral research (pp. 677-696). Thousand Oaks: Sage Publications.

Passeron, J.-C. (1990). Biographies, flux, itinéraires, trajectoires. Revue Française de Sociologie, $31(1), 3-22$.

Pineau, G., \& Le Grand, J.-L. (2013). Les histoires de vie. Paris: PUF Presses Universitaires de France.

Platt, J. (2012). The history of the interview. In J. Gubrium, J. Holstein, A. Marvasti, \& $\mathrm{K}$. McKinney (Eds.), The SAGE handbook of interview research. The complexity of the craft (pp. 9-26). Thousand Oaks: Sage Publications.

Reimer, M., \& Matthes, B. (2007). Collecting event histories with TrueTales: Techniques to improve autobiographical recall problems in standardized interviews. Quality and Quantity, 41(5), 711-725.

Ricoeur, P. (1983). Temps et récit. Paris: Seuil.

Roberts, B. (2002). Biographical research. Buckingham/Philadelphia: Open University Press.

Rosenthal, G. (2004). Biographical research. In C. Seale, G. Gobo, J. Gubrium, \& D. Silverman (Eds.), Qualitative research practice (pp. 48-64). London: Sage Publications.

Schütz, A. (1967). The phenomenology of the social world. Chicago: Northwestern University Press.

Schütze, F. (1983). Biographieforschung und narratives Interview. Neue Praxis, 13(3), 283-293.

Strauss, A. (1959). Mirrors and masks. The search for identity. New York: Free Press.

Thomas, W. I., \& Znaniecki, F. (1974). The Polish peasant in Europe and America. New York: Octogon Books.

Wengraf, T. (2000). Uncovering the general from within the particular. From contingencies to typologies in the understanding of cases. In P. Chamberlayne, J. Bornat, \& T. Wengraf (Eds.), The turn to biographical methods in social science. Comparative issues and examples (pp. 141-123). London: Routledge.

Open Access This chapter is licensed under the terms of the Creative Commons Attribution 4.0 International License (http://creativecommons.org/licenses/by/4.0/), which permits use, sharing, adaptation, distribution and reproduction in any medium or format, as long as you give appropriate credit to the original author(s) and the source, provide a link to the Creative Commons license and indicate if changes were made.

The images or other third party material in this chapter are included in the chapter's Creative Commons license, unless indicated otherwise in a credit line to the material. If material is not included in the chapter's Creative Commons license and your intended use is not permitted by statutory regulation or exceeds the permitted use, you will need to obtain permission directly from the copyright holder.

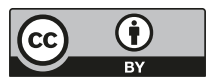

